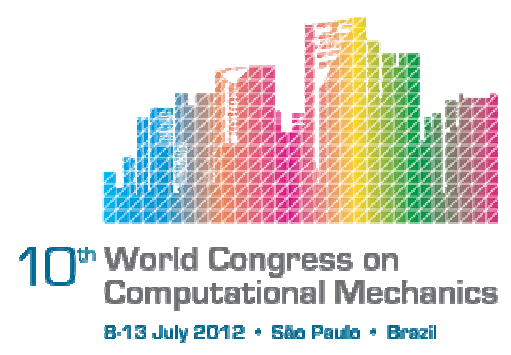

\title{
DYNAMIC ANALYSIS OF BUILDINGS USING THE FINITE ELEMENT METHOD
}

\author{
C. A. T. Lucena ${ }^{1}$, P. C. O. Queiroz $^{2}$, A. L. H. C. El Debs ${ }^{2}$, A. V. Mendonça ${ }^{1}$ \\ ${ }^{I}$ Dept. of Mechanical Engineering. University Federal of Paraiba, Brazil \\ taurinolucena@gmail.com \\ mendonca@ct.ufpb.br \\ ${ }^{2}$ Dept. of Structural Engineering. School of Engineering at the University of São Paulo, Brazil \\ queiroz@sc.usp.br \\ analucia@sc.usp.br
}

\begin{abstract}
This paper deals with finite element vibration analysis of buildings. Each component of building is discretized by its appropriated finite element, that is, bar and beam element for the frame sub-structure, plate finite element for the slabs. By applying compatibility and equilibrium conditions, all sub-structural interactions are incorporated into the system in order to produce a more refined structural analysis of buildings. Other issues for building vibration such as shear deformation, rotatory inertia, and plate-beam eccentricity are investigated as well. Numerical examples are presented and compared with results from commercial numerical packages widespread.
\end{abstract}

Keywords: FEM, Buildings, Dynamic

\section{INTRODUCTION}

The Finite Element Method (FEM) is a numerical technique based on continuum discretization so that the body is divided into finite number of small parts named elements and by expressing the unknown variable fields in terms of assumed approximating functions within each element. These functions are expressed in terms of discrete points named nodes. Clough \& Wilson [1] give interesting historical details about first steps to establish of FEM solutions. For example, in 1960 the designation of finite element method was coined by Ray Willian Clough when a static analysis of stress plane problem [2] was modeled using that new born technique. Since then FEM solutions have been received many other contribution and applied to a variety engineering problems. This is the case for vibration analysis of frame and plate [3]-[6]. Additional details on vibration FEM solutions including more complex structures such as shells can be found elsewhere, for example [3]-[9].

A specific topic in building structural analysis has been studied by many researchers is associated with eccentric relative position beam-plate at each floor. One of many strategies has established to deal with eccentricity problem is the rigid offset approach. Harik et al. [14] presented an analytical solution, Mukhopadhya [15] proposed a finite difference solution, Harik et al. [14], Araújo [16], Sapountzakis et al. [17], Deb et al. [18]-[19], gave finite element solutions, Tanaka et al. built boundary element solutions.

In this paper the influence of effects such as shear deformation, rotatory inertia, and platebeam eccentricity into building vibration responses are analyzed by house-made program called EDF and commercial packaged Ansys. 


\section{ASSEMBLY OF MASS AND STIFFNESS MATRICES}

In this section the strategy of assembling of each elemental mass and stiffness matrices into global matrices of the building is briefly discussed. The building analysis can be split into major problems, namely space frame and plates (in bending and/or in tension), and their interaction effects, see Figure 1 .

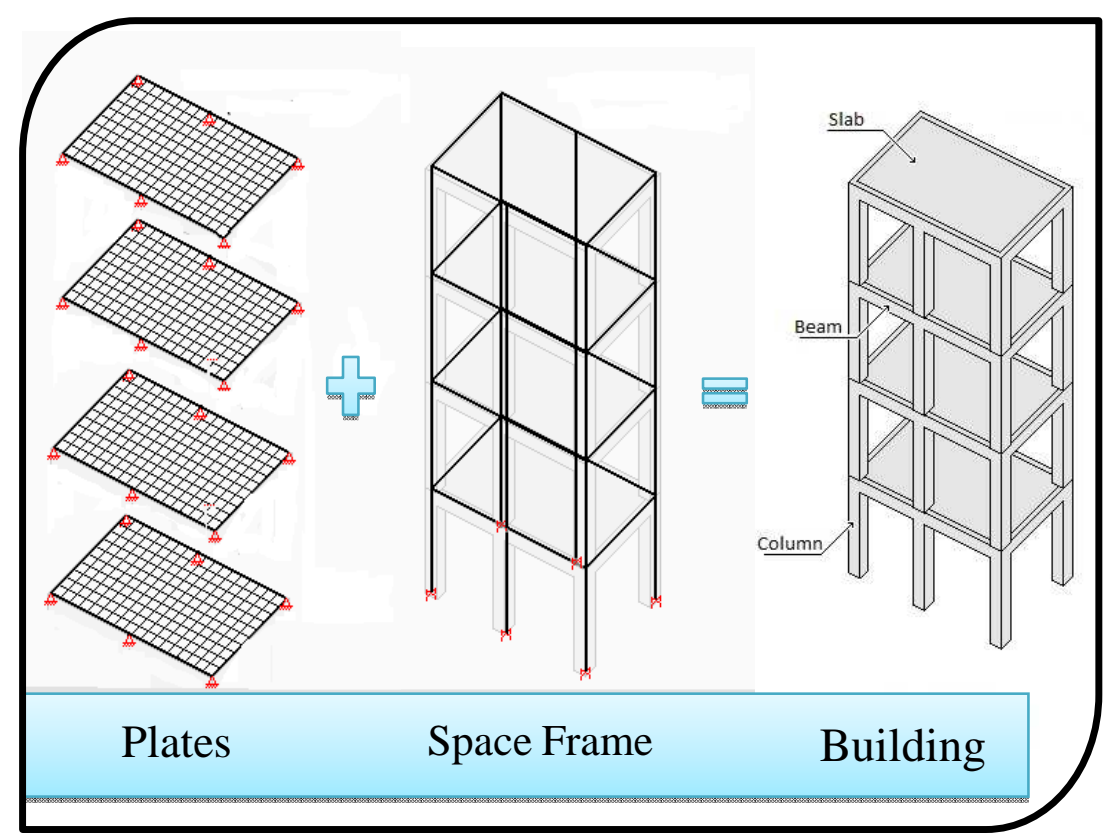

Figure 1. Building structural components.

In a space frame problem, the efforts in each member can be simultaneously mobilized due to axial, bending, and torsional actions. Both mass and stiffness matrices of a 3D frame member are wellknown and they can be found in many works, such as Queiroz [9] and Lucena [10]. If only an isolated space frame is considered, the assembly of the global matrices can be done as shown in appendix Figure 14(a). In this paper for the stretching and bending plate vibration problems were implemented respectively two elements namely CST (Constant Stress Triangle) and DST (Discrete Shear Triangle). Mathematical details for both elements can be found elsewhere, for example Petyt [12], Batoz and Lardeur [13], Lucena [10]. A relevant topic is the study of influence of beam-plate eccentricity of each floor to the global response of the building, see Figure 2.

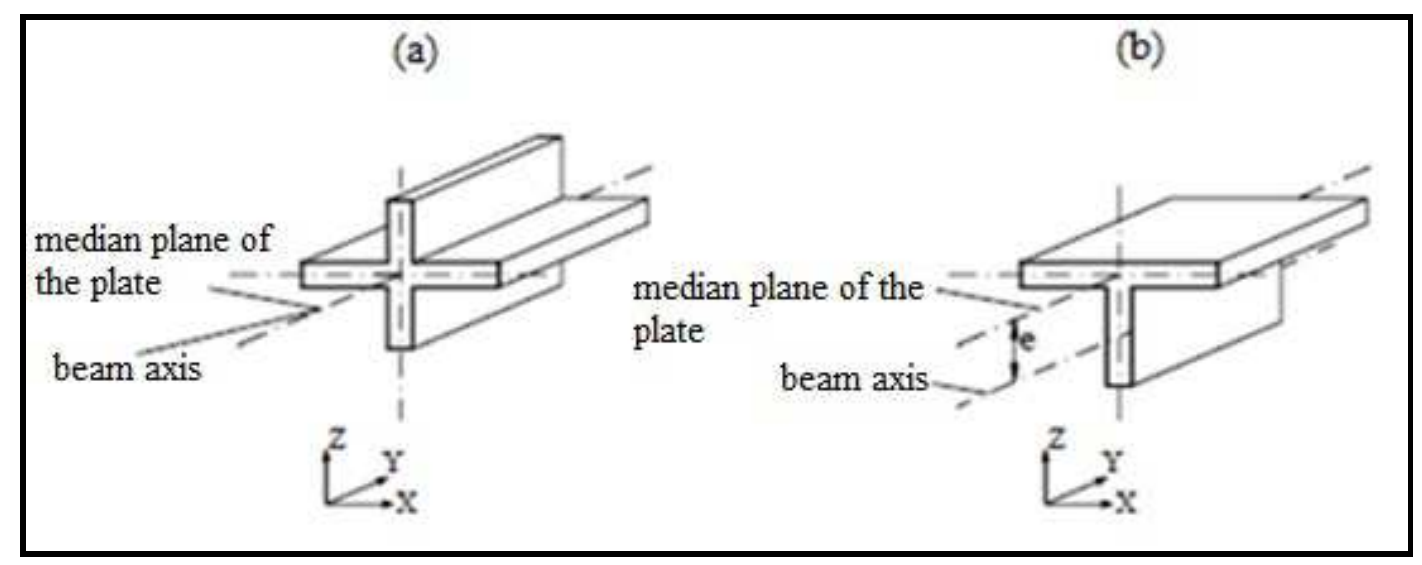

Figure 2. (a) Beam-plate configuration: (a) non-eccentric case; (b) eccentric case. 
When a beam and a plate have no eccentricity implies nodal points of beam element coincide with some nodes of plate element, see Figure 2(a). In this case, no additional step is required and both beam and plate elemental contributions can be directly and independently assembled in global matrices of the structure. On other hand when beam-plate eccentricity exists (very usual situation in buildings, see Figure 2(b) it is necessary to reposition the degrees of freedom of the beam (usually located on its centroidal axis) onto a plane of the plate (usually median plane, see Figure 3) or vice-versa. Due to change of nodal location of beam, the energy conservation of system requires mass and stiffness matrices of the beam are transformed too.

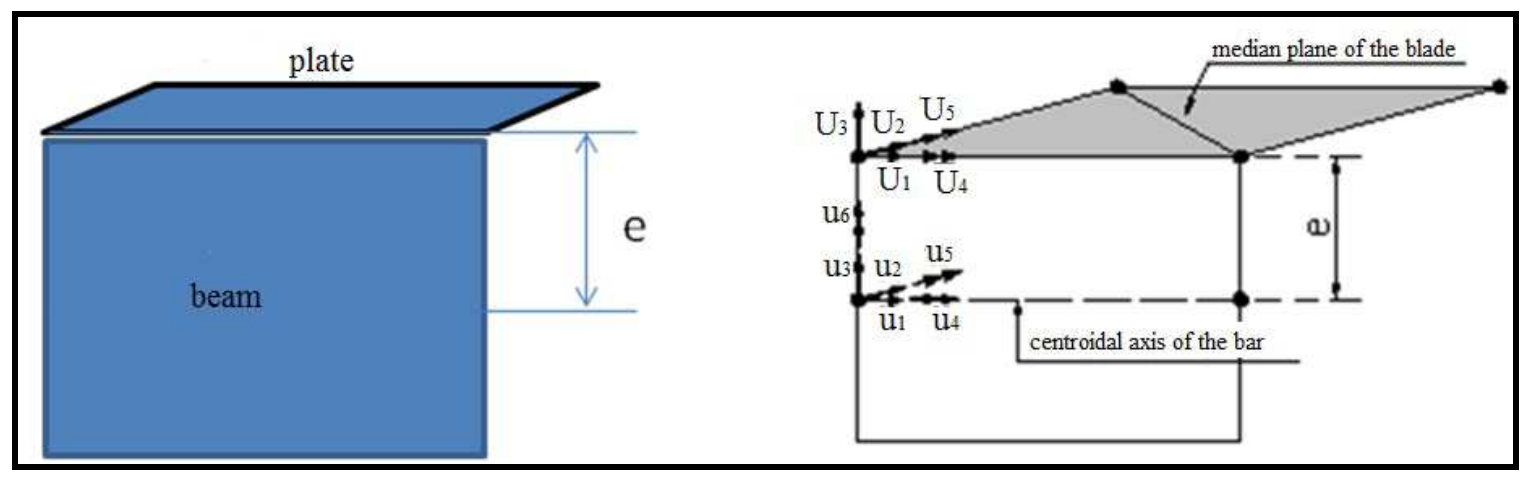

Figure 3. Local displacement vectors of the beam and their eccentricity.

Let there be $\{\mathrm{u}\}$ and $\{\mathrm{U}\}$ the global displacement vectors at beam centroidal axe and at plate median plane, respectively, and a relation can be written as follows.

$$
\left\{\begin{array}{l}
u_{1} \\
u_{2} \\
u_{3} \\
u_{4} \\
u_{5} \\
u_{6}
\end{array}\right\}=[\psi]\left[\begin{array}{l}
U_{1} \\
U_{2} \\
U_{3} \\
U_{4} \\
U_{5} \\
U_{6}
\end{array}\right\} \text { where } \quad[\psi]=\left[\begin{array}{cccccc}
1 & 0 & 0 & 0 & 0 & e \\
0 & 1 & 0 & 0 & -e & 0 \\
0 & 0 & 1 & 0 & 0 & 0 \\
0 & 0 & 0 & 1 & 0 & 0 \\
0 & 0 & 0 & 0 & 1 & 0 \\
0 & 0 & 0 & 0 & 0 & 1
\end{array}\right]
$$

The final transformed matrices of the beam with respect to plate median plane system are:

$$
\begin{aligned}
& {\left[K^{P}\right]=[\psi]^{T}[K][\psi]} \\
& {\left[M^{P}\right]=[\psi]^{T}[M][\psi]}
\end{aligned}
$$

In addition, the assembly of the transformed matrices given in $\mathrm{Eq}(2)$ and $\mathrm{Eq}(3)$ can be done as shown in appendix - Figure 14(b). For the building problem, an assembling strategy is to create three subsets of typical nodes. The first is associated with (stretching/bending) plate nodes that do not receive any contribution from space frame nodes, called "Plate nodes". The second subset is called "Mixed nodes" and it receives both plate and space frame contributions". The third subset called "Frame nodes" is formed by off-plate nodes. The subset dimensions are respectively given by $5 N_{L}, 6 \mathrm{~L}_{\mathrm{M}}$ and $6 \mathrm{~L}_{\mathrm{F}}$. Let there be a plate element with node orientation $(\mathrm{i}, \mathrm{j}, \mathrm{k})$ and interacting with 
two $(i, j)$ and $(j, 1)$ oriented frame elements, see Figure 4 . Then, the assembly of building matrices from all elemental contribution can be done as shown in appendix - Figure 14(c).

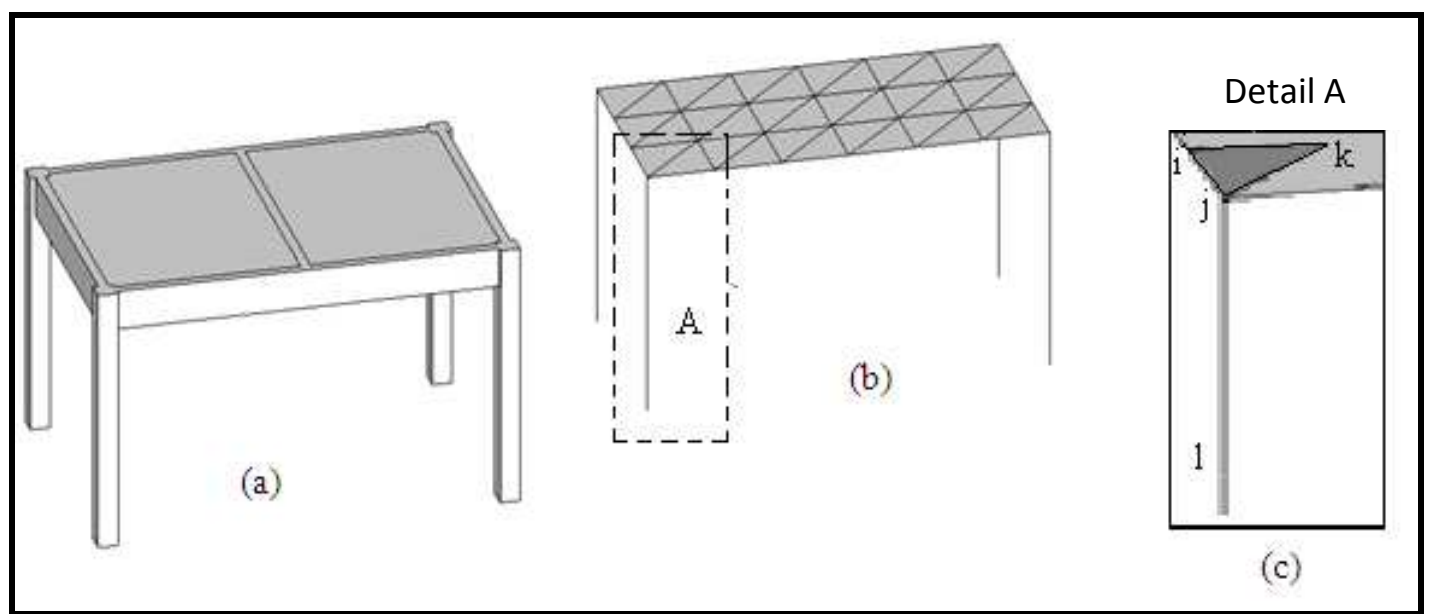

Figure 4. (a) Real structure; b) Discretized structure; c) Beam-Plate elements interacting at node j.

\section{NUMERICAL RESULTS}

All mathematical details of the finite element solution described in this paper were encoded in the program called EDF.FOR, see Lucena [11]. In order to check EDF.FOR performance, vibration analysis of two structures (space frame and four-storey building) is presented. The results of this house-made program are compared to commercial package ANSYS outputs.

\subsection{Space Frame}

This example was originally proposed by Petyt [12], see Figura 5 . The mechanical and dimensions of the members are: Young modulus, $E=219,9 \times 10^{9} \mathrm{~N} / \mathrm{m}^{2}$; density, $\rho=7900 \mathrm{~kg} / \mathrm{m}^{3}$ and length, $L=1 \mathrm{~m}$. Both Euler-Bernoulli and Timoshenko models are taken into account and the results from both programs are shown in Table 1.

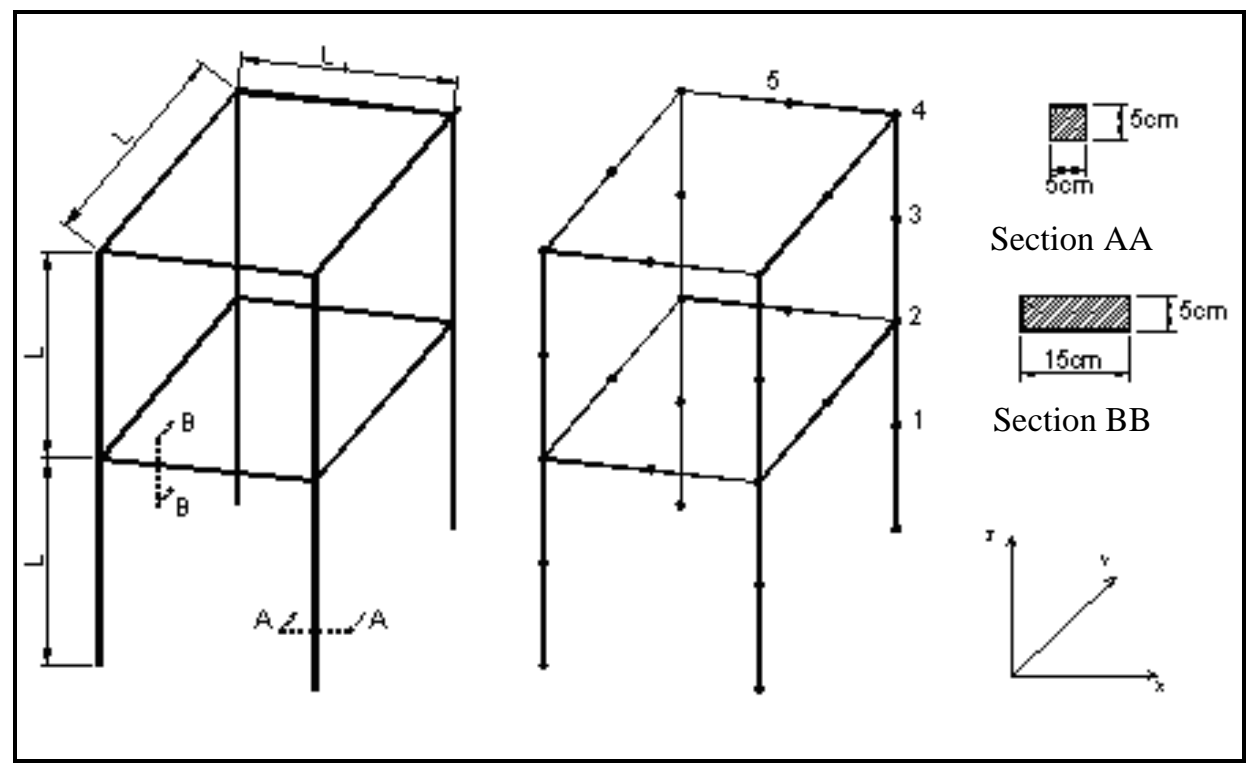

Figura 5. Space frame and its discretization. 
Table 1. Frequency results $(\mathrm{Hz})$

\begin{tabular}{ccccccc}
\hline \multirow{2}{*}{$\begin{array}{c}\text { Mode } \\
\text { Number }\end{array}$} & \multicolumn{2}{c}{ EDF } & $\begin{array}{c}\text { Model } \\
\text { Euler }^{1}\end{array}$ & Model Euler & Ansys & \multicolumn{2}{c}{ EDF } & Ansys \\
\hline 1 & 11.808796 & 11.808643 & 11.808 & 11.76402563 & 11.76387476 & 11.774 \\
2 & 11.808796 & 11.808643 & 11.808 & 11.76402563 & 11.76387476 & 11.808 \\
3 & 15.4457303 & 15.411955 & 15.412 & 15.3966169 & 15.36295663 & 15.391 \\
4 & 34.1154902 & 34.112377 & 34.111 & 33.98476808 & 33.98170942 & 33.992 \\
5 & 34.1154902 & 34.112377 & 34.111 & 33.98476808 & 33.98170942 & 34.108 \\
6 & 43.433024 & 43.330254 & 43.329 & 43.29169296 & 43.18938625 & 43.263 \\
7 & 123.299665 & 123.18396 & 122.05 & 122.9237718 & 122.8097391 & 121.99 \\
8 & 125.736015 & 125.6063 & 124.36 & 125.3376278 & 25.20986295 & 124.3 \\
9 & 145.00127 & 144.88404 & 143.99 & 144.3209478 & 144.2060394 & 143.88 \\
10 & 154.139833 & 153.98871 & 153.63 & 153.4583667 & 153.3105848 & 153.45 \\
11 & 154.139833 & 153.98871 & 153.63 & 153.4583667 & 153.3105848 & 153.63 \\
12 & 157.719628 & 157.54384 & 156.15 & 156.8369922 & 156.6655141 & 156.02 \\
13 & 169.296732 & 169.14853 & 168.87 & 164.9313557 & 164.6636774 & 164.81 \\
14 & 169.296732 & 69.148533 & 168.87 & 168.3485203 & 168.2042581 & 168.69 \\
15 & 169.626978 & 169.32003 & 169.31 & 168.3485203 & 168.2042581 & 168.87 \\
16 & 190.617268 & 190.16343 & 190.15 & 185.4286436 & 185.0307075 & 185.12 \\
17 & 225.625976 & 225.32584 & 223.8 & 223.4873333 & 223.2009211 & 221.94 \\
18 & 225.625976 & 225.32584 & 223.8 & 223.4873333 & 223.2009211 & 223.76 \\
19 & 239.219681 & 238.87411 & 238.54 & 236.8261719 & 236.4969022 & 237.25 \\
20 & 246.457127 & 246.0154 & 245.72 & 243.4084611 & 243.0062042 & 244.01 \\
\hline
\end{tabular}

For sake of a better visualization, the results of Table 1 are plotted, see Figure 6 .

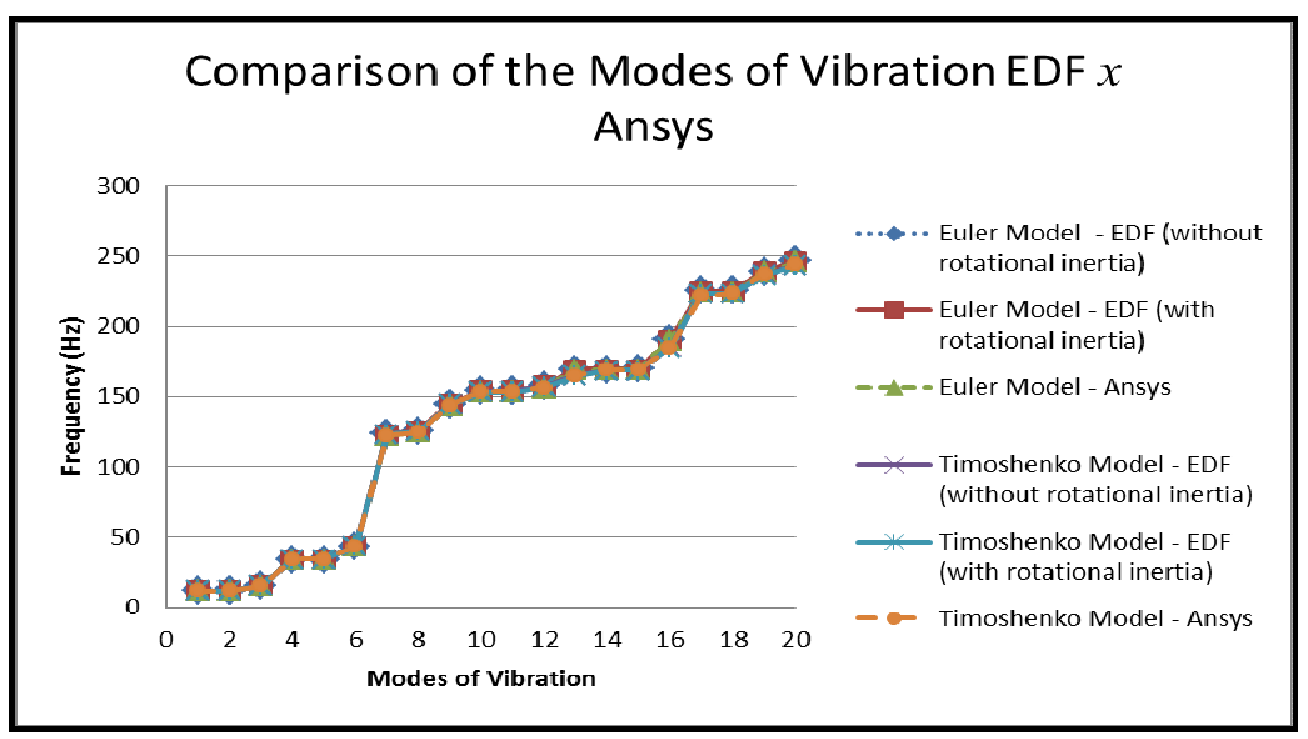

Figure 6. Space frame results.

\footnotetext{
${ }^{1}$ No rotatory inertia

${ }^{2}$ Rotatory inertia
} 


\subsection{Four-storey building}

In this example vibration analysis for variety slender ratios of structural components of a fourstorey building is done, see Figure 7. In addition the influence of plate-beam eccentricity, shear deformation and rotatory inertia effects in building vibration behavior is also considered. For all components, the following values for mechanical properties are set: Young modulus, $E=21 \times 10^{9} \mathrm{~N} / \mathrm{m}^{2}$; density, $\rho=2500 \mathrm{~kg} / \mathrm{m}^{3}$. For plate elements, Poisson's ratio is $v=0,30$ and all results are done using DKT element for bending plate contributions into the problem, except when is explicitly warned.

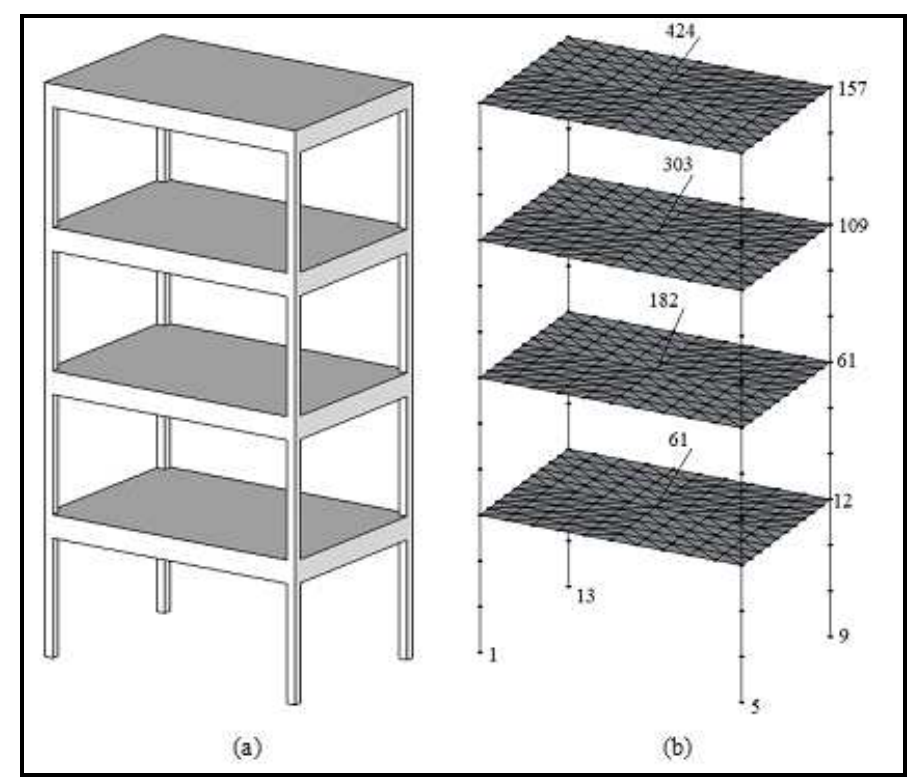

Figure 7. Four-storey building: (a) geometry, (b) discretization

The study was divided into three parts: firstly beam slender ratio influence in building vibration is analyzed under following assumptions. All plates have $10 \mathrm{~cm}$ constant thickness and all columns have a typical $(20 \times 20) \mathrm{cm}$ square cross-section. A $(20 x h) \mathrm{cm}$ cross-section is set for all beams and two values are assumed for $h$.

Table 2 - Frequencies $(\mathrm{Hz})$ for non-eccentric case: (plate $\mathrm{h}=0.10 \mathrm{~m})-($ beam $\mathrm{h}=0.50 \mathrm{~m})$

\begin{tabular}{ccccc}
\hline \multirow{2}{*}{$\begin{array}{c}\text { Mode } \\
\text { Number }\end{array}$} & \multicolumn{2}{c}{ Euler-Bernoulli's beam } & \multicolumn{2}{c}{ Timoshenko's beam } \\
\cline { 2 - 5 } & EDF & ANSYS & EDF & ANSYS \\
\hline 1 & 1.033634243568042 & 1.0335 & 1.026163178509705 & 1.0261 \\
2 & 1.051321466365204 & 1.0512 & 1.042713789161397 & 1.0426 \\
5 & 3.083254020001557 & 3.0829 & 3.059042393325857 & 3.0586 \\
10 & 6.133236349035065 & 6.1322 & 6.090743238372382 & 6.0897 \\
15 & 10.699237061042660 & 10.651 & 10.629603122588180 & 10.582 \\
20 & 17.936212724087930 & 17.847 & 17.743458077855130 & 17.655 \\
25 & 24.823920795071000 & 24.497 & 24.609889249841980 & 24.338 \\
30 & 30.606705038030040 & 30.556 & 30.441299394962270 & 30.389 \\
35 & 40.816869158106850 & 40.234 & 40.348166803980430 & 39.775 \\
40 & 47.758536892544060 & 46.995 & 46.961864549614620 & 46.235 \\
45 & 51.998620754883710 & 50.961 & 51.399784463171740 & 50.532 \\
\hline
\end{tabular}


Table 3 -Frequencies $(\mathrm{Hz})$ for eccentric case: $($ plate $\mathrm{h}=0.10 \mathrm{~m})-($ beams $\mathrm{h}=0.50 \mathrm{~m})$

\begin{tabular}{ccccc}
\hline \multirow{2}{*}{ Mode $\mathrm{N}^{\mathrm{o}}$} & \multicolumn{2}{c}{ Euler-Bernoulli's beam } & \multicolumn{2}{c}{ Timoshenko's beam } \\
\cline { 2 - 5 } & EDF & ANSYS & EDF & ANSYS \\
\hline 1 & 1.061105210654078 & 1.0600 & 1.052878883863958 & 1.0518 \\
2 & 1.069293282336665 & 1.0684 & 1.060060841738016 & 1.0593 \\
5 & 3.124465230676489 & 3.1205 & 3.098809652840658 & 3.0951 \\
10 & 6.143373253738758 & 6.1371 & 6.100320485187121 & 6.0943 \\
15 & 12.818649259830260 & 12.742 & 12.705003588424920 & 12.630 \\
20 & 20.492074748603760 & 20.333 & 20.289840881110260 & 20.189 \\
25 & 27.490250113643460 & 27.043 & 27.221579028101290 & 26.782 \\
30 & 31.587787232354530 & 31.561 & 31.405497422876140 & 31.376 \\
35 & 43.533910399307850 & 42.826 & 43.291480405625190 & 42.625 \\
40 & 50.194220128101630 & 48.459 & 50.045250822373090 & 48.315 \\
45 & 53.158655994945020 & 51.930 & 52.177054714839100 & 51.022 \\
\hline
\end{tabular}

Table 4 - Non-eccentric case: (plate $\mathrm{h}=0.10 \mathrm{~m})-($ beam $\mathrm{h}=0.80 \mathrm{~m})$

\begin{tabular}{ccccc}
\hline \multirow{2}{*}{ Mode $N^{o}$} & \multicolumn{2}{c}{ Euler-Bernoulli's beam } & \multicolumn{2}{c}{ Timoshenko's beam } \\
\cline { 2 - 5 } & EDF & ANSYS & EDF & ANSYS \\
\hline 1 & 0.97777737465142289 & 0.97767 & 0.9698353132263625 & 0.96973 \\
2 & 0.9796925061525277 & 0.97959 & 0.9722366292403232 & 0.97213 \\
5 & 2.845731851293956 & 2.8454 & 2.824630045531332 & 2.8243 \\
10 & 5.497798210133395 & 5.4970 & 5.459845809899770 & 5.4591 \\
15 & 14.831850434225120 & 14.708 & 14.716596862275180 & 14.596 \\
20 & 24.099711540057980 & 23.971 & 23.685053731839450 & 23.524 \\
25 & 30.405686660826370 & 29.792 & 30.182141949107190 & 29.584 \\
30 & 35.744411088574980 & 34.730 & 35.716495690795860 & 34.703 \\
35 & 45.569945054429910 & 44.477 & 44.918095831465320 & 43.615 \\
40 & 53.179774314214070 & 52.360 & 52.789080492217070 & 51.107 \\
45 & 59.693230687868560 & 58.063 & 58.688231895087200 & 58.148 \\
\hline
\end{tabular}

Table 5 - Frequencies $(\mathrm{Hz})$ for eccentric case: (plate $\mathrm{h}=0.10 \mathrm{~m})-($ beam $\mathrm{h}=0.80 \mathrm{~m})$

\begin{tabular}{ccccc}
\hline \multirow{2}{*}{ Mode No } & \multicolumn{2}{c}{ Euler-Bernoulli's beam } & \multicolumn{2}{c}{ Timoshenko's beam } \\
\cline { 2 - 5 } & EDF & ANSYS & EDF & ANSYS \\
\hline 1 & 0.9813890571155897 & 0.98293 & 0.9732779425289443 & 0.98125 \\
2 & 0.9863427704428834 & 0.98709 & 0.9786756420889796 & 0.98592 \\
5 & 2.861052757951518 & 2.8606 & 2.839452174069153 & 2.8580 \\
10 & 5.500626179040095 & 5.4950 & 5.462595784379647 & 5.4940 \\
15 & 16.706018819362260 & 16.555 & 16.558035888165120 & 16.411 \\
20 & 28.044182252379500 & 27.728 & 27.343770282073450 & 27.046 \\
25 & 31.864847655130900 & 31.222 & 31.620607422652910 & 30.992 \\
30 & 36.210165576136050 & 35.291 & 35.955307263621120 & 34.968 \\
35 & 47.867119090662290 & 44.218 & 47.636652351543720 & 44.003 \\
40 & 55.012062684831130 & 52.910 & 54.902568106283380 & 51.712 \\
45 & 58.919546022347830 & 55.373 & 58.042801175215840 & 54.735 \\
\hline
\end{tabular}




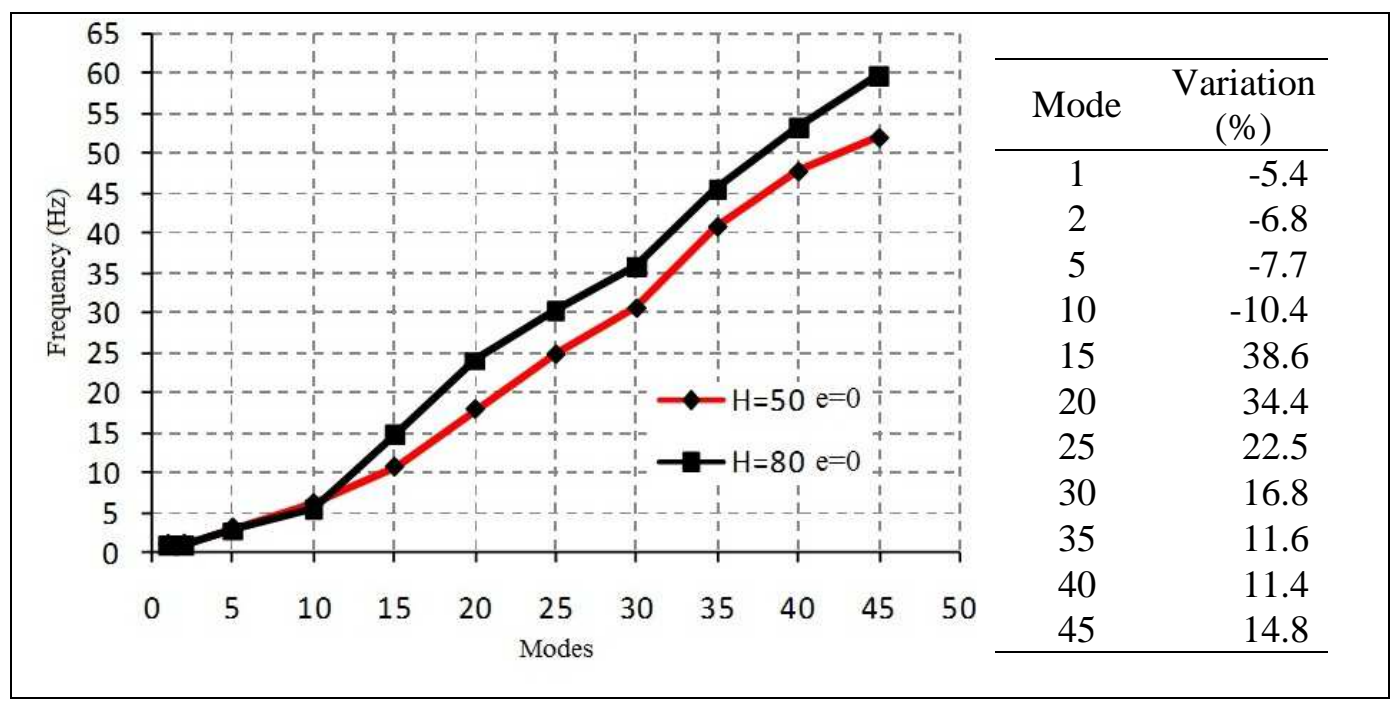

Figure 8 . Beam ridigity influence on non-eccentric case

For sake a better visualization, the results of non-eccentric plate-beam case shown in Table 2 and Table 4 are plotted together in Figure 8. The eccentric plate-beam results in Table 3 and Table 5 are plotted in Figure 9.

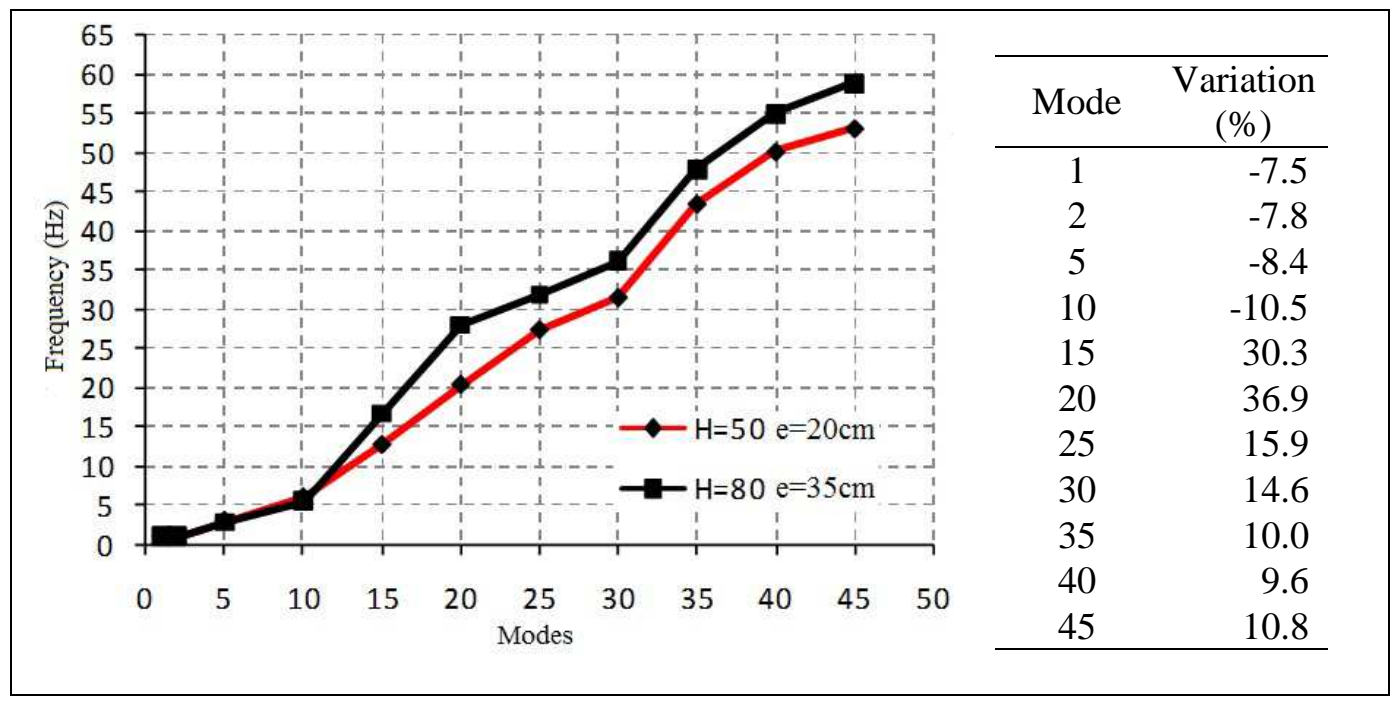

Figure 9. Beam ridigity influence on eccentric case

If the results of the thinner beams $(\mathrm{h}=50)$ in Figure 8 and in Figure 9 are taken as reference values, the first ten natural frequencies for thicker beams $(\mathrm{h}=80)$ decreased respectively between $5.4 \%$ and $10.4 \%$ for non-eccentric problem and $7.5 \%$ and $10.5 \%$ for eccentric case. On the other hand when range between 15th and 45th modes is checked, it can be seen that natural frequencies of the thicker beam problem are increased between $11.4 \%$ and $34.4 \%$ for the non-eccentric case and $9.6 \%$ to $36,9 \%$ for the eccentric problem. These major discrepancies are certainly due to more severe bending mode activation for thicker beams. A typical case is observed about 20th mode where mode configurations for both cases $(\mathrm{h}=50$ and $\mathrm{h}=80)$ are shown in Figure 10. 


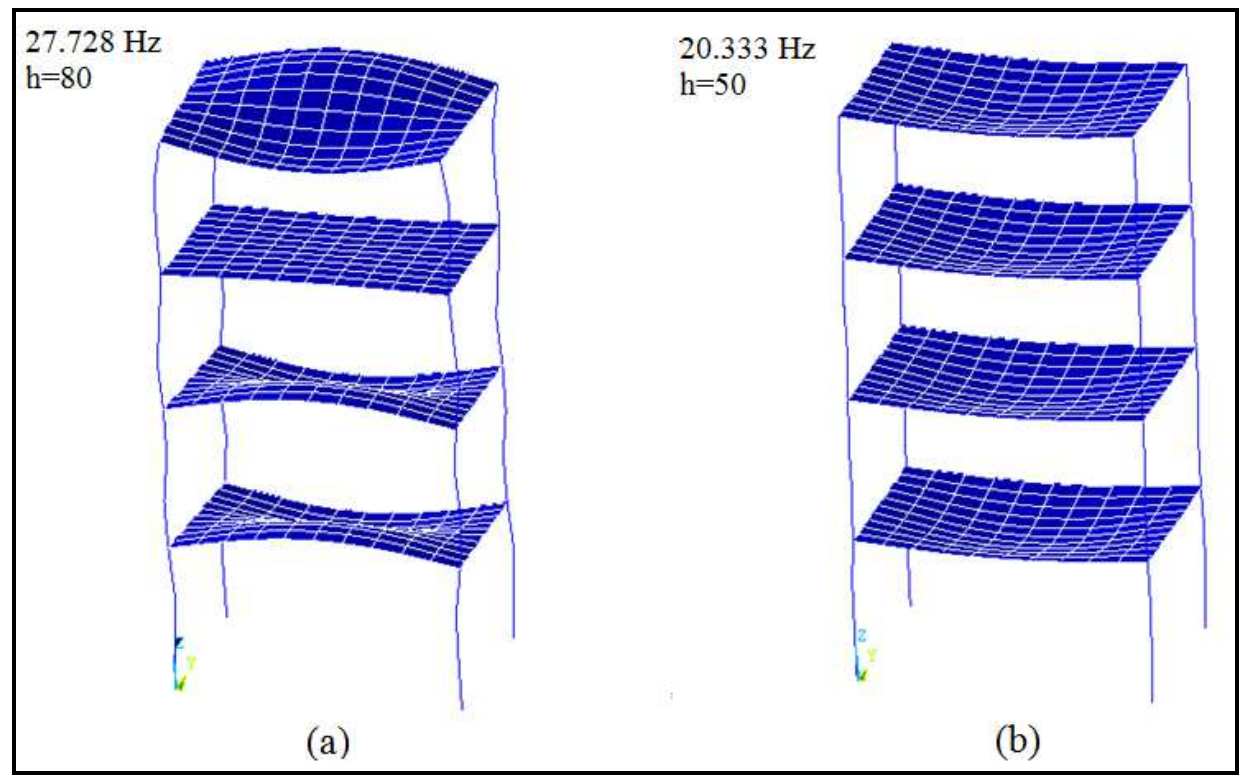

Figure 10. Settings of the 20th mode (a) $h=80 ;$ (b) $h=50$

The second part of the building vibration analysis is concerned on plate slender ratio influence in building responses. Hence some assumption is done: beam-plate problem is always eccentric, all beams have the same cross-section $(20 x 80) \mathrm{cm}$, and all columns cross-section is square with dimension $20 \mathrm{~cm}$.

The influence of plate thickness variation in the building vibration behavior is initially done and shear deformation effects are not included (classical plate model). Analyses for three thicknesses of the plate 10, 20 and $30 \mathrm{~cm}$ are independently done. By selecting DKT element, EDF and Ansys results are shown in Table 5, Table 6 and Table 7. For sake a better visualization the outputs are plotted together in Figure 11.

Table 6. Frequencies $(\mathrm{Hz})$ eccentric case: $($ plate $\mathrm{h}=0.20 \mathrm{~m})-($ beam $\mathrm{h}=0.80 \mathrm{~m})-$ column $(0.20 \times 0.20) \mathrm{m}$

\begin{tabular}{ccccc}
\hline \multirow{2}{*}{ Mode $\mathrm{N}^{\mathrm{o}}$} & \multicolumn{2}{c}{ Euler-Bernoulli } & \multicolumn{2}{c}{ Timoshenko } \\
\cline { 2 - 5 } & EDF & ANSYS & EDF & ANSYS \\
\hline 1 & 0.8293750409755191 & 0.83044 & 0.8227936436689241 & 0.82388 \\
2 & 0.8340287604609957 & 0.83445 & 0.8276543806135503 & 0.82810 \\
5 & 2.417162832657765 & 2.4167 & 2.399140468688497 & 2.3988 \\
10 & 4.634355366607846 & 4.6318 & 4.602253750231750 & 4.5998 \\
15 & 18.129607984803820 & 18.046 & 17.833315482366810 & 17.714 \\
20 & 28.109150010122560 & 28.145 & 27.991753951863470 & 28.027 \\
25 & 42.387049407920120 & 41.670 & 41.322183753097150 & 36.889 \\
30 & 45.099012533007870 & 44.012 & 43.801345471503300 & 42.697 \\
35 & 58.162430748004090 & 57.335 & 57.756874147415520 & 55.909 \\
40 & 64.49996888117163 & 64.405 & 63.066791827934590 & 62.789 \\
45 & 65.345883383739720 & 65.287 & 63.707594933563410 & 63.631 \\
\hline
\end{tabular}

Table 7. Frequencies $(\mathrm{Hz})$ eccentric case: $($ plate $\mathrm{h}=0.30 \mathrm{~m})-($ beam $\mathrm{h}=0.80 \mathrm{~m})-$ column $(0.20 \mathrm{x} 0.20) \mathrm{m}$

\begin{tabular}{ccccc}
\hline \multirow{2}{*}{ Mode $\mathrm{N}^{\mathrm{o}}$} & \multicolumn{2}{c}{ Euler-Bernoulli } & \multicolumn{2}{c}{ Timoshenko } \\
\cline { 2 - 5 } & EDF & ANSYS & EDF & ANSYS \\
\hline 1 & 0.7314230031823287 & 0.73224 & 0.7259813796638660 & 0.72678 \\
2 & 0.7357778526412748 & 0.73612 & 0.7303252140427594 & 0.73065 \\
5 & 2.131274143423030 & 2.1311 & 2.115764573823893 & 2.1156 \\
10 & 4.079733654343166 & 4.0784 & 4.051566408859258 & 4.0503 \\
\hline
\end{tabular}




\begin{tabular}{lllll}
\hline 15 & 16.630121151899140 & 16.612 & 16.579815076595760 & 16.562 \\
20 & 29.002845646654430 & 29.057 & 28.904550876622010 & 28.960 \\
25 & 44.219052338206040 & 43.821 & 43.227278646436850 & 42.832 \\
30 & 55.184507852580140 & 54.130 & 54.682751123006350 & 53.618 \\
35 & 63.994146800298080 & 63.636 & 62.540515496259820 & 62.281 \\
40 & 65.285823976308460 & 65.233 & 63.617427580988740 & 63.571 \\
45 & 65.604209407136820 & 65.584 & 63.909799670753620 & 63.882 \\
\hline
\end{tabular}

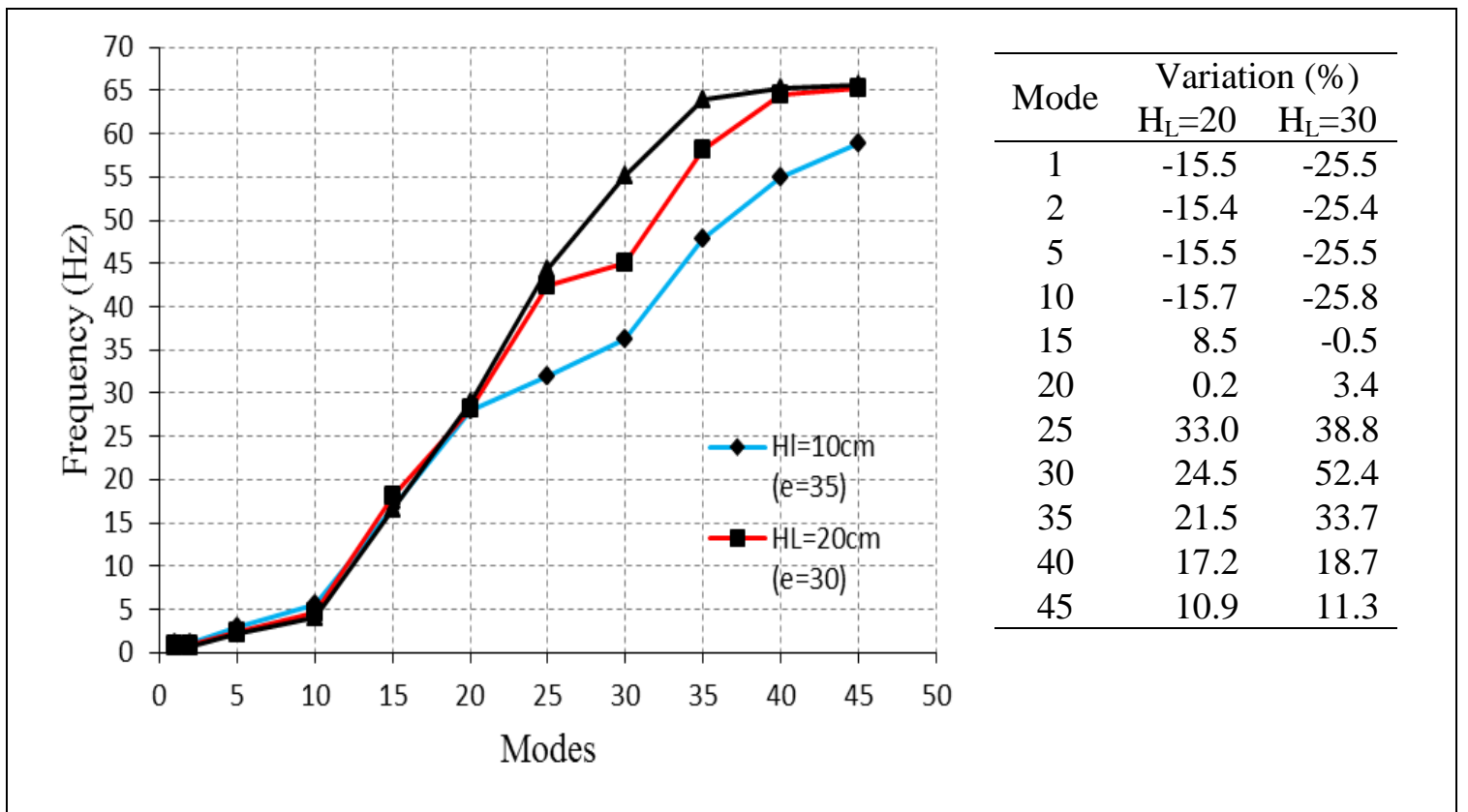

Figure 11. Plate ridigity influence for eccentric case.

By assuming thinner plate results as reference values, it can be seen there is a decreasing of natural frequencies until 10th mode $(15.7 \%$ for $\mathrm{h}=20$ and $25.8 \% \mathrm{~h}=30 \mathrm{~cm})$. For higher modes (until 40th) the thicker plates increase natural frequencies. A complementary study of the earlier problem in order to check shear deformation effect in all building components is done as well. The vibration analysis is modeled by EDF (using both DST plate and Timoshenko beam elements) only and the results are shown in Table 8 and Figure 12.

Table 8. Frequencies $(\mathrm{Hz})$ incorporating shear deformation effects for plate and beam DST elements for plate and Timoshenko's beam

\begin{tabular}{|c|c|c|c|}
\hline \multirow{2}{*}{$\begin{array}{c}\text { Mode } \\
\text { Number }\end{array}$} & \multicolumn{3}{|c|}{$\begin{array}{l}\text { DST elements for plate and Timoshenko's beam } \\
\quad(\text { beam } \mathrm{h}=0.80 \mathrm{~m}), \text { column }(0.20 \times 0.20) \mathrm{m}\end{array}$} \\
\hline & $\begin{array}{c}\text { plate }(\mathrm{h}=10 \mathrm{~cm}) \\
\mathrm{e}=35 \mathrm{~cm}\end{array}$ & $\begin{array}{c}\text { Plate }(\mathrm{h}=20 \mathrm{~cm}) \\
\mathrm{e}=30 \mathrm{~cm}\end{array}$ & $\begin{array}{c}\text { Plate }(\mathrm{h}=30 \mathrm{~cm}) \\
\mathrm{e}=25 \mathrm{~cm}\end{array}$ \\
\hline 1 & 0.9732744677093985 & 0.8227266718092883 & 0.7257943847425563 \\
\hline 2 & 0.9786749015925560 & 0.8276392615450652 & 0.7302702382631422 \\
\hline 5 & 2.839449996129212 & 2.399105589554805 & 2.115640255869238 \\
\hline 10 & 5.462592105083606 & 4.602237793494199 & 4.051521762546975 \\
\hline 15 & 16.526669415551750 & 17.803260799809390 & 16.557976877659960 \\
\hline 20 & 27.326817262917330 & 27.979698423999490 & 28.856040883028330 \\
\hline 25 & 31.503036906434580 & 41.135618019665660 & 42.754293742999600 \\
\hline 30 & 35.822998742607440 & 43.680109794382580 & 54.197368729408740 \\
\hline 35 & 47.543719135812010 & 57.320421256622860 & 62.500908874808780 \\
\hline 40 & 54.688519389612870 & 62.974795699346510 & 63.596349288916920 \\
\hline 45 & 57.948194188817130 & 63.703264647440940 & 63.906124089558420 \\
\hline
\end{tabular}




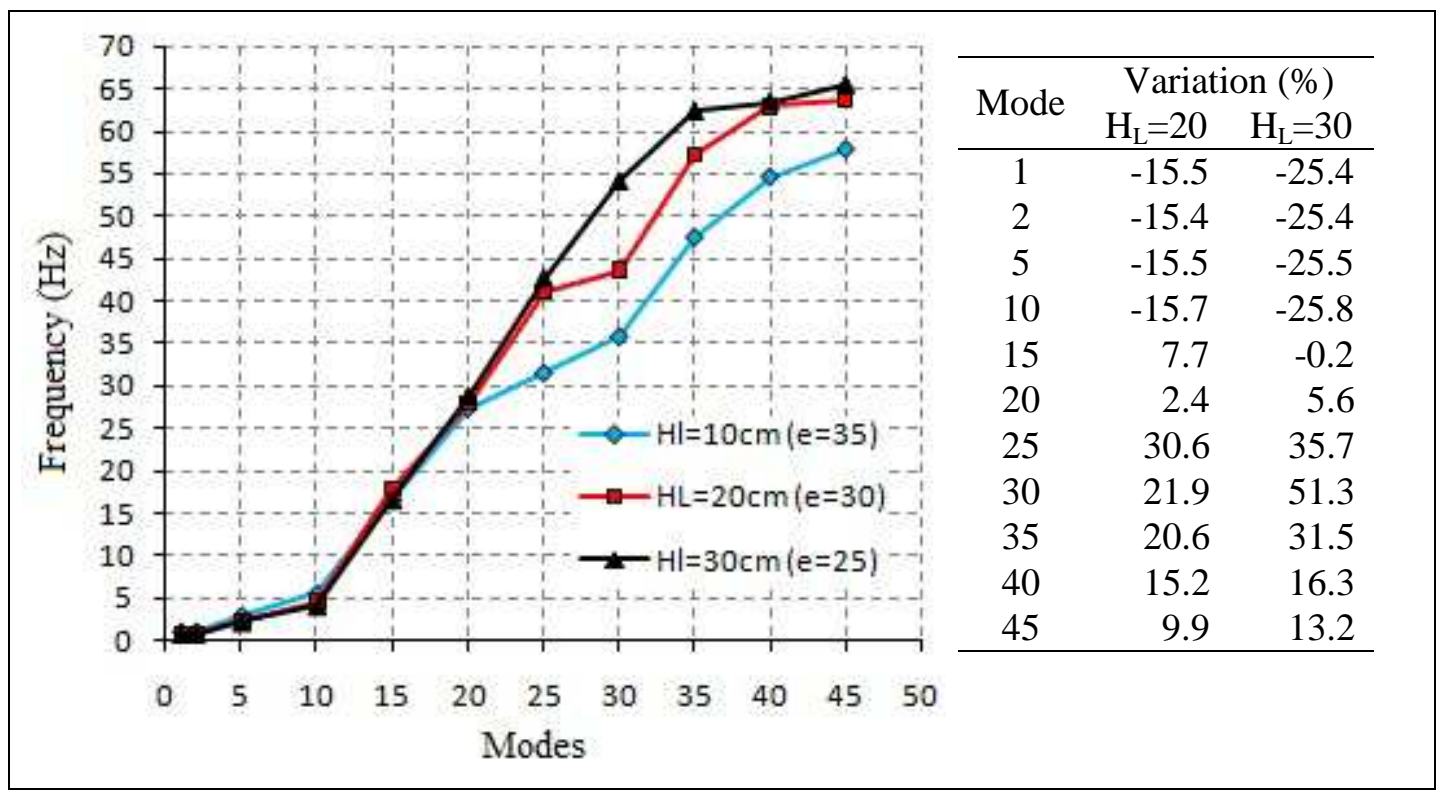

Figure 12. Plate rigidity influence and shear deformation effects on eccentric case

The results show there are no significative changes until 45th mode vibration responses when shear deformation was taken into account.

At last third part of the building vibration analysis in this paper is concerned about influence of variation of column cross-section dimensions. The assumptions for this analysis are: all plates has thickness $10 \mathrm{~cm}$ and a cross-section $(20 x 80) \mathrm{cm}$ is set for all beams. Two cross-section dimensions are set to the all columns, $(20 \times 20) \mathrm{cm}$ and $(40 \times 40) \mathrm{cm}$.. The EDF and Ansys results for $(40 \times 40) \mathrm{cm}$ crosssection columns in Table 9 are shown only. In Figure 13 both column cross-sections analyses are plotted.

Tabela 9. Frequencies $(\mathrm{Hz})$ eccentric case: (plate $\mathrm{h}=0.10 \mathrm{~m})-($ beam $\mathrm{h}=0.80 \mathrm{~m})$ - column $(0.40 \mathrm{x} 0.40) \mathrm{m}$

\begin{tabular}{ccccc}
\hline \multirow{2}{*}{$\begin{array}{c}\text { Mode } \\
\text { Number }\end{array}$} & \multicolumn{2}{c}{ Euler-Bernoulli's beam } & \multicolumn{2}{c}{ Timoshenko's beam } \\
\cline { 2 - 5 } & EDF & ANSYS & EDF & ANSYS \\
\hline 1 & 2.984353648437686 & 2.9881 & 2.897020117432950 & 2.9021 \\
2 & 3.054102673539377 & 3.0591 & 2.942812889441475 & 2.9500 \\
5 & 9.212390099187937 & 9.2083 & 8.899009872081662 & 8.9050 \\
10 & 17.312097285493380 & 17.097 & 17.159695509391720 & 16.950 \\
15 & 20.308793665539740 & 20.198 & 19.716451606859310 & 19.628 \\
20 & 32.328691239677820 & 31.618 & 31.930651694976390 & 31.330 \\
25 & 35.467487874409320 & 34.664 & 34.106090408379160 & 33.445 \\
30 & 45.352876833737640 & 43.417 & 44.819779928222640 & 42.518 \\
35 & 50.625448328801750 & 48.568 & 49.406304454311320 & 47.507 \\
40 & 59.774830750619830 & 53.851 & 59.611505646993460 & 53.757 \\
45 & 62.338234193366160 & 60.002 & 61.645643383805460 & 59.406 \\
\hline
\end{tabular}




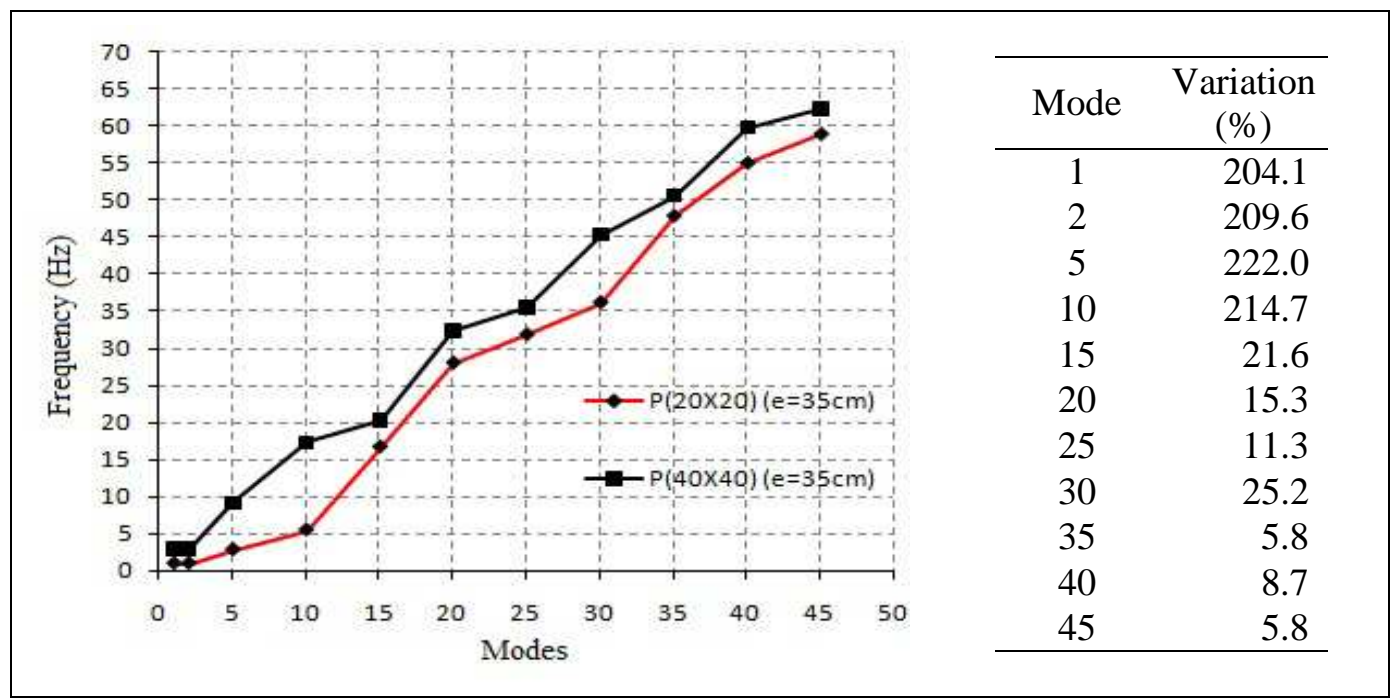

Figure 13. Column rigidity influence on eccentric case

The results show lower modes are strongly affected when the column cross-section dimensions are changed.

\section{CONCLUSIONS}

The numerical results in the paper suggest results from EDF house-made program are in a good accordance with those run with commercial package Ansys. The changes in four-storey building vibration responses are analyzed, when slender ratios of each group of structural components are independently changed. The most severe changes for lower natural frequencies of the building is due to column cross-section variation. Shear deformation effects produce slight changes to lower natural frequencies of the building when compared to classical models.

\section{Acknowledgments}

The authors thank Capes and CNPq for financial support for this research.

\section{REFERENCES}

[1] Clough, R. W.; Wilson E. L. "Early Finite Element Research at Berkeley", Present at the Fifth U.S. National Conference on Computational Mechanics, 1990.

[2] Clough, R. W., "The Finite Element Method in Plane Stress Analysis", Proc. 2nd ASCE Conf. On Eletronic Computation, Pittsburg, Pa. Sept. 1960.

[3] Anderson, R.G., Irons, B.M., Zienkiewicz, O.C. Vibration and stability of plates using finite elements. Int. Journal of Solids and Structures, 4 1031-1005, 1968.

[4] Dickinson, S.M., Henshel, R.D. Clough-Tocher triangular plate-bending element in vibration, AIAA Journal 7 560-561, 1969. 
[5] TOCHER, J. L. Analysis of Plate Bending Using Triangular Elements. University of California, Berkeley, Ph.D. Dissertation, 1962.

[6] Mackerle, J. Finite element vibration analysis of beams, plates and shells. Shock and Vibration, 6 97-109, 1969.

[7] Samanta, A. \& Mukhopadhyay, M. Finite element static and dynamic analyses of folded plates. Eng. Struct., 21 277-871 1999.

[8] Lim, G.H. Vibration of plates and shells using finite elements (1996-1997). Finite Elem. Anal. Design, 31 223-30, 1999.

[9] Queiroz, P. C. O. Análise estática e dinâmica de estruturas reticuladas: ambiente de simulação em JAVA. Universidade Federal da Paraíba, Dissertação de mestrado 2010.

[10] Lucena, C. A. T. Análise estática e dinâmica de edifícios industriais utilizando-se o método dos elementos finitos. Universidade Federal da Paraíba, Dissertação de Mestrado, 2011.

[11] Viana, H. R. G. Análise estática e vibratória de placas utilizando-se o método dos elementos finitos. Universidade Federal da Paraíba, Dissertação de mestrado, 2008.

[12] Petyt, M. Introduction to finite element vibration analysis. Cambridge University Press, 1990.

[13] Batoz, J.L. \& Lardeur, P.A. A discrete shear triangular nine dof element for the analysis of tick to very thin plates. Int. J. Num. Meth. Eng. V.28. p. 533-560, 1989.

[14] Harik, I. E. \& Guo, M. Finite Element Analysis of Eccentrically Stiffened Plates in Free Vibration. Computer and Structures. 6, Vol. 49, pp. 1007-1015, 1993.

[15] Mukhopadhya, M. Stiffened Plates in Bending. Computer and Structures. 4, Vol. 50, pp. 541548, 1994.

[16] Araújo, J. M. Avaliação dos métodos simplificados para cálculo de lajes maciças apoiadas em vigas flexíveis. Teoria e Prática na Engenharia Civil. Vol. 12, PP. 1-11, 2008.

[17] Sapountzakis, E. J. \& Katsikadelis, J. T. Analysis of Plates Reinforced with Beams. Computacional Mechanics. Vol. 26, pp. 66-74, 2000.

[18] Deb, A. \& Botton, M. Finite element models for Stiffened plates under transverse loading. Computer and Structures. 3, Vol. 28, pp. 362-372. 1988.

[19] Deb, A. \& Deb, M. K. Analysis of Orthotropically Modeled Stiffened Plates. International Journal of Solids Structures. 5, Vol. 25, pp. 647-667, 1991.

[20] Tanaka, M. \& Bercin, A. N. Static bending analysis of stiffened plates using the boundary element method. Engineering Analysis with Boundary Elements. Pp. 147-154, 1998. 


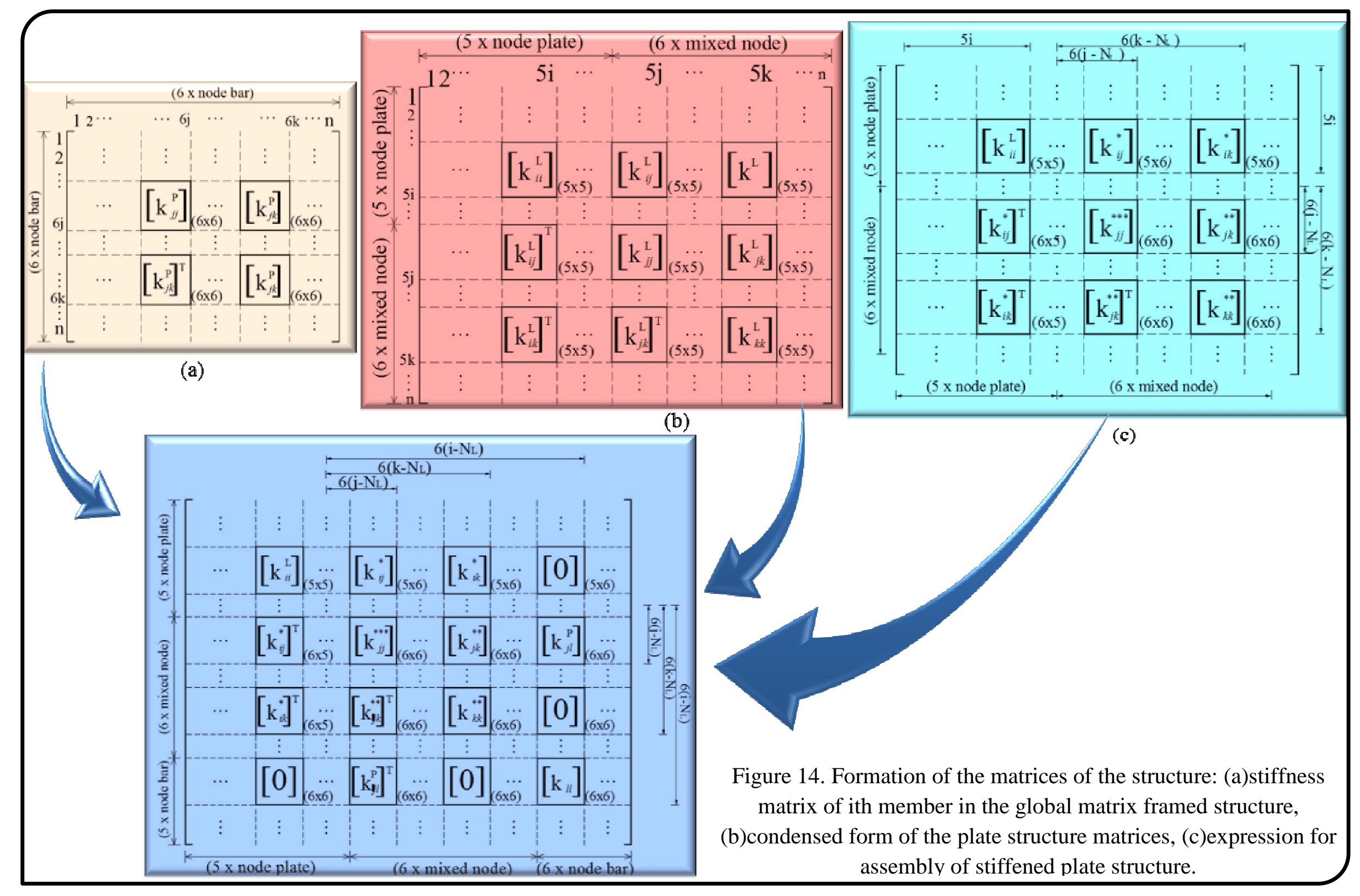


The sub matrices in Figure 14, are given by:

$$
\begin{aligned}
& {\left[k_{i j}^{*}\right]_{5 \times 6}=\left[\left[\mathrm{k}_{\mathrm{ij}}^{\mathrm{L}}\right]_{5 \times 6}[0]_{5 \times 1}\right]} \\
& {\left[k_{i k}^{*}\right]_{5 \times 6}=\left[\left[\mathrm{k}_{\mathrm{ik}}^{\mathrm{L}}\right]_{5 \times 5}[0]_{5 \times 1}\right]_{5 \times 6}} \\
& {\left[k_{i j}^{* *}\right]=\left[\begin{array}{cc}
{\left[k_{j j}^{L}\right]_{x 5}} & {[0]_{5 \times 1}} \\
{[0]_{x 5}} & 0
\end{array}\right]_{6 \times 6}+\left[\mathrm{k}_{\mathrm{jj}}^{\mathrm{p}}\right]_{6 \times 6}} \\
& {\left[k_{j k}^{* * *}\right]_{6 \times 6}=\left[\begin{array}{cc}
{\left[k_{j k}^{L}\right]_{5 \times 5}} & {[0]_{5 x 5}} \\
{[0]_{1 \times 5}} & {[0]}
\end{array}\right]_{6 \times 6}+\left[\mathrm{k}_{\mathrm{jk}}^{\mathrm{p}}\right]_{6 \times 6}} \\
& {\left[k_{k k}^{* *}\right]_{6 \times 6}=\left[\begin{array}{ll}
{\left[k_{k k}^{L}\right]_{5 \times 5}} & {[0]_{5 x 1}} \\
{[0]_{1 \times 5}} & {[0]}
\end{array}\right]_{5 \times 6}+\left[\mathrm{k}_{\mathrm{kk}}^{\mathrm{p}}\right]_{6 \times 6}}
\end{aligned}
$$

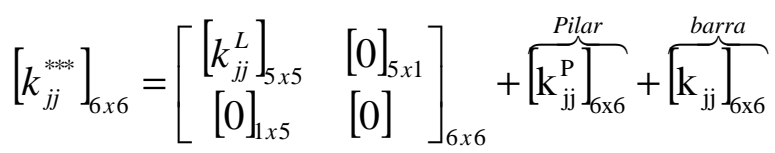

